\title{
Intra-operative low-dose ketamine does not reduce the cost of post-operative pain management after surgery: a randomized controlled trial in a low-income country
}

\author{
Luca Ragazzoni, ${ }^{1}$ Arthur Kwizera, ${ }^{2}$ Marta Caviglia, ${ }^{1}$ Moran Bodas, ${ }^{1}$ Jeffrey Michael Franc, ${ }^{1,3}$ \\ Hannington Ssemmanda, ${ }^{2}$ Alba Ripoll-Gallardo, ${ }^{1}$ Francesco Della-Corte, ${ }^{1}$ Annet Alenyo-Ngabirano ${ }^{2}$
}

1. CRIMEDIM - Research Center in Emergency and Disaster Medicine, Università del Piemonte Orientale, Novara, Italy.

2. Department of Anaesthesia, Makerere University, Kampala, Uganda.

3. Department of Emergency Medicine, University of Alberta, Edmonton, AB, Canada.

\begin{abstract}
Background: In developing countries, post-operative pain remains underestimated and undertreated due to economic constraints, lack of awareness and limited resources. In contrast, ketamine is an effective, readily available, easy to use and inexpensive drug frequently used in poor settings.

Objectives: The aim of this study was to explore the overall reduction in the medication treatment cost of acute post-operative pain by adding intra-operative low-dose ketamine to traditional intravenous morphine for surgery in a low-income country.

Methods: A double blind randomized controlled trial with placebo-controlled parallel group was performed in Mulago National Hospital (Uganda). Consenting adults scheduled for elective surgery were randomized into two study arms: Group K received ketamine $0.15 \mathrm{mg} / \mathrm{kg}$ bolus at induction and a continuous infusion of $0.12 \mathrm{mg} / \mathrm{kg} / \mathrm{hour}$ till start of skin closure; Group C (control) received normal saline. Both groups received Morphine $0.1 \mathrm{mg} / \mathrm{kg}$ IV at debulking. The total medication cost was registered. NRS pain scores and other measurements such vital signs and incidence of major and minor side effects were also recorded.
\end{abstract}

Results: A total of 46 patients were included. Patients' baseline characteristics were comparable in both groups. No statistically significant difference was found between the groups concerning the overall medication cost of post-operative pain management. Pain scores, patients' satisfaction in the first 24 hours after surgery and hospital length of stay were similar in both groups.

Conclusion: Our results do not support the utilization of intra-operative low dose ketamine as a cost-saving post-operative pain treatment strategy for all types of surgery in low-resource settings.

Keywords: Post-operative pain management, ketamine, low-income country, RCT.

DOI: https://dx.doi.org/10.4314/ahs.v19i4.35

Cite as: Ragazzoni L, Kwizera A, Caviglia M, Bodas M, Franc JM, Ssemmanda H, Ripoll-Gallardo A, Della-Corte F, Alenyo-Ngabirano A. Intra-operative low-dose ketamine does not reduce the cost of post-operative pain management after surgery: a randomized controlled trial in a low-income country. Afri Health Sci.2019;19(4):3127-3135. https:/ / dx.doi.org/10.4314/abs.v19i4.35

\section{Introduction}

In low-income countries, the cost of perioperative inter-

\section{Correspondence author:}

Luca Ragazzoni,

CRIMEDIM - Research Center

in Emergency and Disaster Medicine,

Università del Piemonte Orientale, Novara, Italy.

CRIMEDIM, Via Lanino 1, 28100 Novara, Italy.

Mobile: +39 3498761209 | office: +390321 660620

| fax: +390321660531

Email: luca.ragazzoni@med.uniupo.it ventions represents one of the main barriers for accessing essential surgical care ${ }^{1}$. In these settings, post-operative pain remains extremely underestimated and undertreated mainly due to procurement difficulties and the prohibitive costs of common analgesic medications. ${ }^{2-9}$

Ketamine is an anesthetic drug frequently used in low-resource settings as it is safe, easy to use and inexpensive ${ }^{10,11}$. Ketamine has been increasingly used in sub-anesthetic doses as an adjuvant to opioids for acute pain management ${ }^{12-19}$. The balance of evidence in the current literature demonstrates that low-dose ketamine given as pre-emptive analgesia, reduces post-operative pain and morphine consumption and delays the patients' request 
for rescue analgesia ${ }^{13,18-22}$. However, whether this reduction in the consumption of analgesic drugs entails also a significant decrease in the costs of post-operative pain management is unknown.

The aim of this study was to compare the overall medication cost of acute post-operative pain management in the first 24 hours when adding intra-operative low-dose ketamine to intravenous morphine after surgery in a low-income country. It was hypothesized that the overall medication cost would be lower for patients receiving ketamine compared with placebo.

\section{Methods}

This manuscript adheres to the CONSORT guidelines for randomized trials.

\section{Ethical approval}

This study was approved by the Makerere University's Institutional Review Board (IRB \#43, October 23 ${ }^{\text {rd }}, 2013$ ) and written informed consent was obtained from all subjects participating in the trial. The trial was registered prior to patient enrollment at the Pan African Clinical Trials Registry (PACTR201410000854305, Principal investigator: Dr. Luca Ragazzoni, Date of registration: October 1, 2014).

\section{Study design}

This study was a double blind randomized controlled trial with placebo-controlled parallel group (single center-based randomization $(1: 1)$ ) conducted at the Mulago National Hospital, Uganda. Patients were randomly assigned to one of the two parallel groups in 1:1 ratio to receive either intra-operative low-dose ketamine (Group $\mathrm{K}$ ) or a control solution of normal saline (Group C). Patients were randomly assigned to Group K or Group C, received intended treatment and were analyzed for outcomes (Fig. 1). An independent data monitoring committee reviewed the blinded data for patient safety.

\section{Study setting and population}

Forty-six patients, 23 males and 23 females, scheduled for elective surgery under general anesthesia in the Mulago Hospital were enrolled between March and May 2014. All patients met the following inclusion criteria: 18-70 years old, ASA physical status I and II and acute or chronic disease requiring surgery under general anesthesia.

Patients with chronic pain under regular treatment with pain killers, alcohol and drug abuse cases, obese (BMI > 30) subjects, neurosurgery, obstetrics and gynecology cases, patients too sick to communicate, and patients with psychiatric disorders were excluded from the study.

As per agreement with the local authorities, the following general rules for stopping the study at any time were set: withdrawal of patient's consent, serious adverse effects and/or unacceptable safety incidents, any case of new external information arisen during the conduct of the study that either convincingly answered the primary study question or that raised serious safety issues.

\section{Randomization}

An equal number of envelopes for each treatment group were prepared using a computerized random number generator by a study assistant who did not take part in any subsequent part of the study, and was not in contact with the rest of the study team throughout the entire study duration. He prepared 46 identical sequentially numbered, opaque, sealed and stapled envelopes; 23 envelopes contained instructions for mixing solutions for Group K, and the other 23 for Group C. The envelopes were kept in a file with the principal investigator.

After a patient was recruited by a member of the study team, a second study assistant selected an envelope randomly from the file and mixed the study solution according to the instructions in the envelope as per the patient's weight. He then resealed the envelope, placed it in a different file, and gave the study solutions labeled with the patient identity code (the same as that on the selected envelope) to the anesthesiologist in charge; thereafter, he did not partake in any subsequent part of the study. Both ketamine and normal saline study solutions had the same physical properties: clear liquids with no distinctive odor. Therefore, they could not be identified or differentiated by sight or smell by anyone in the operating theatre.

The allocation sequence was concealed from both the study team and study assistants. The blinded study team labeled the data collection sheet with the patient identity code, and, in the operating theatre, verified the proper timing of study solution administration.

\section{Study protocol}

Theater lists were reviewed on the day before surgery and eligible patients noted. On the day of surgery, a member of the study team evaluated the patient in the waiting area of the operation theater. Study details were explained to those who met the inclusion criteria. After obtaining written informed consent, patients were made familiar with the Numeric Rating Scale (NRS) with a pain intensity scale ranging from " 0 " (no pain) to "10" (worst possible 
pain). Patients were then randomized and allocated to the two groups according to the procedures previously described.

A baseline set of physiological parameters (weight, height, non-invasive blood pressure, oxygen saturation, respiratory rate and heart rate) was measured for each patient in the waiting area. Anesthetic pre-medication was given in the operating theater and consisted of ranitidine $50 \mathrm{mg}$, metoclopramide $10 \mathrm{mg}$, and fentanyl $2 \mu \mathrm{g} / \mathrm{kg}$, all administered IV. Anesthesia was induced with propofol $2 \mathrm{mg} / \mathrm{kg}$ and tracheal intubation was facilitated with succinylcholine $1 \mathrm{mg} / \mathrm{kg}$. Patients were maintained with isoflurane inhaled at an end-tidal concentration of $1.5-2.5 \%$ in $50 \%$ oxygen/air mixture, fentanyl $1-2 \mathrm{mcg} / \mathrm{kg} / \mathrm{h}$ and atracurium when needed.

Immediately after the induction of anesthesia, a bolus dose of $0.15 \mathrm{mg} / \mathrm{kg}$ of ketamine was injected to the patients in Group $\mathrm{K}$, following the similar protocol proposed by Parikh et al. ${ }^{19}$, while the same volume of normal saline was given to the patients in Group C. The bolus dose was then followed, till the end of skin closure, by a continuous infusion of $0.12 \mathrm{mg} / \mathrm{kg} / \mathrm{h}$ of ketamine in Group $\mathrm{K}$ and normal saline in Group C18. Morphine 0.1 $\mathrm{mg} / \mathrm{kg}$ IV was given at the end time of debulking in both groups. No vital signs were recorded by the blinded observer intra-operatively.

At the end of surgery, the inhalation anesthetic was discontinued, and the residual neuromuscular blockade antagonized with neostigmine $40 \mu \mathrm{g} / \mathrm{kg}$ and atropine 20 $\mu \mathrm{g} / \mathrm{kg}$. Patients were extubated when reflexes, an adequate breathing pattern and recovery of muscle strength were restored. After surgery, all patients were monitored in the post-anesthesia care unit (PACU) for one hour to ensure a modified Aldrete score $\geq 9$. During this time, a blind observer assessed the NRS pain score, vital signs and the incidence of major and minor side effects.

If NRS was $\geq 4$, morphine was given as $2 \mathrm{mg}$ increments until NRS $<4$. During the 4 hours between the scheduled assessments, a rescue dose of diclofenac 50-75 mg or tramadol 50-100 $\mathrm{mg}$ was given if requested by patients. During the 24 hours assessment all cases of post-operative nausea and vomiting (PONV) were treated with metoclopramide $10 \mathrm{mg}$.

\section{Outcome measures}

\section{Primary outcome}

19 April 2014: 1 EUR=3,470.84 UGX; 1 USD= 2,513.33
UGX). The milligrams of the analgesic drugs used for the single patients (morphine and ketamine) were noted, as well as the milligrams of alternative analgesic drugs (diclofenac and tramadol) and of drugs for PONV treatment (metoclopramide). The overall cost was then calculated adding together the total cost of ketamine (6.60 UGX per mg), morphine (203.00 UGX per mg), and additional medications: tramadol (8.33 UGX per mg), diclofenac (0.34 UGX per mg) and metoclopramide (2.97 UGX per mg).

\section{Secondary outcomes}

1. Clinical evaluation: NRS pain scores, vital signs (heart rate, noninvasive blood pressure, respiratory rate and oxygen saturation) and incidence of major and minor side effects related to morphine administration such as respiratory depression (respiratory rate $<10$ breaths/min), PONV and pruritus were assessed and measured every 15 minutes during the first hour after surgery in PACU and every 4 hours during the consecutive 24 hours. Psycho mimetic effects related to ketamine were also assed during the first hour after surgery.

2. Analgesic acceptance: patients' satisfaction was assessed at the 24th hour by using a 4-point Likert scale (1 "insufficient" to 4 "excellent").

3. Hospital length of stay: patients were followed up from the day of surgery to hospital discharge.

\section{Data analysis}

Before the study, the investigators hypothesized that the overall medication cost of pain management of patients who receive intra-operative low-dose ketamine would be $30 \%$ lower than that of patients who do not receive ketamine. The primary outcome (measure of the overall medication costs) was fit to a linear regression equation with four factors: group (Group K vs. Group C), ASA score, age, and gender. The null hypothesis of all regression coefficients equal to zero was tested against the alternative hypothesis that some coefficients were not equal to zero. P-values less than 0.05 were considered significant for all statistical tests.

A sample size of 46 was chosen to give an $80 \%$ power of detecting an effect size of 0.3 in the primary outcome. The software A-priori Sample Size Calculator for Multiple Regression1 was used to calculate the sample size ${ }^{23}$. Due to the small sample size of this study, no interim analyses for efficacy or futility were done. During the trial, there were no changes made to the study methodology. 


\section{Results}

In the enrollment phase, 246 patients were assessed for eligibility; of these, 196 did not meet the inclusion criteria, two declined to participate, and two showed severe hypertension, resulting in a total of 200 patients excluded from the study (Fig.1). Among the 46 patients enrolled,
23 were females and 23 were males; according to gender, patients were similarly distributed between the two study groups: 11 women and 12 men in Group K, 12 women and 11 men in Group C. Six patients, 4 in Group K and 2 in Group C, were lost to follow-up, due to failure to register their discharge date on the file; therefore, only 40 patients were assessed for hospital length of stay.

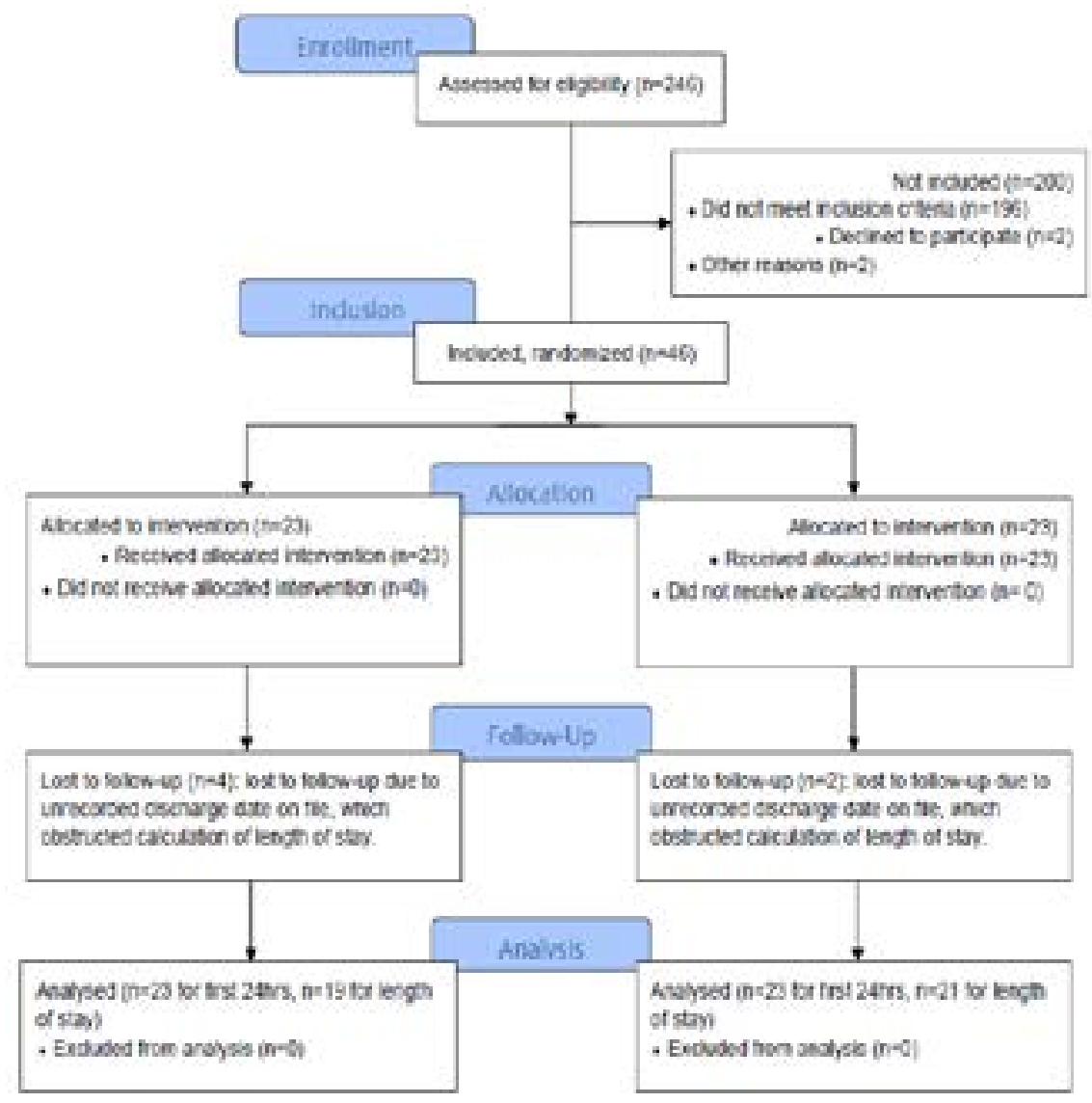

Figure 1: Participants \& study flow chart

Baseline characteristics with regard to age, weight, height, and duration of infusion of study solutions were equivalent in the two study groups (Table 1). Surgical characteristics (major and minor procedures) were comparable between both groups.
Table 2 shows a summary of all elective procedures performed during the research, which included general, oral, urologic and orthopedic surgery. 
Table 1. Baseline demographic and clinical characteristics for each group

\begin{tabular}{lrrrrr}
\hline Variable & $\begin{array}{l}\text { Overall } \\
(\text { mean } \pm \text { SD) }\end{array}$ & \multicolumn{1}{l}{$\begin{array}{l}\text { Ketamine } \\
(\text { mean } \pm \text { SD) }\end{array}$} & $\begin{array}{l}\text { Control } \\
(\text { mean } \pm \text { SD) }\end{array}$ & $\begin{array}{l}\text { Mean } \\
\text { difference }\end{array}$ & p-value \\
\hline Age (years) & $41.78 \pm 15.56$ & $42.52 \pm 15.56$ & $41.04 \pm 15.87$ & 0.31 & 0.53 \\
Weight $(\mathrm{kg})$ & $62.76 \pm 12.25$ & $60.69 \pm 9.5$ & $64.82 \pm 14.39$ & 1.08 & 0.13 \\
$\begin{array}{l}\text { Height }(\mathrm{cm}) \\
\begin{array}{l}\text { Duration of infusion } \\
\text { (min) }\end{array}\end{array}$ & $164.18 \pm 8.52$ & $165.31 \pm 8.40$ & $162.66 \pm 8.72$ & 0.91 & 0.63 \\
\hline
\end{tabular}

Table 2. Surgical procedures

\begin{tabular}{|c|c|c|c|c|c|c|c|}
\hline ieral Surgery & & al Surgery & $\mathbf{n}$ & Urologic Surgery & $\mathbf{n}$ & Orthopedic Surgery & $\mathbf{n}$ \\
\hline Thyroidectomy & 10 & Tumor excision & 9 & Prostatectomy & 2 & ORIF* & 21 \\
\hline Mastectomy & 5 & $\begin{array}{l}\text { (parotid or neck } \\
\text { mass) }\end{array}$ & 1 & $\begin{array}{l}\text { Penis plication } \\
\text { plasty }\end{array}$ & 1 & $\mathrm{TBW}^{* *}$ & 1 \\
\hline Appendicectomy & 4 & Mastoidectomy & 1 & Uretheroplasty & 1 & $\begin{array}{l}\text { Tumor excision } \\
\text { (scapula) }\end{array}$ & 1 \\
\hline Cholecistectomy & 2 & Caldwell Luc & 1 & 1 & & & \\
\hline Choledocotomy & 1 & $\begin{array}{l}\text { Lateral } \\
\text { rhinotomy }\end{array}$ & 1 & 1 & & & \\
\hline Hemicolectomy & 1 & Timpanoplasty & 1 & 1 & & & \\
\hline Splenectomy & 1 & & & & & & \\
\hline $\begin{array}{l}\text { Mass excision } \\
\text { (Laparotomy) }\end{array}$ & 1 & & & & & & \\
\hline
\end{tabular}

\section{Primary outcome}

The mean medication cost of post-operative analgesia during the first 24 hours after surgery was 2586.86 UGX for Group K and 2844.74 UGX for Group C (Fig. 2). There was no statistically significant difference between the two groups $(p=0.40)$ (95\% CI for the difference: -769 , +311) even after controlling for ASA, gender, and age.
Data from all the 46 enrolled patients were available for this analysis. Mean consumption of post-operative morphine was $5.6 \mathrm{mg}$ in Group $\mathrm{K}$ and $6.9 \mathrm{mg}$ in Group C. Ten patients required additional analgesia, 3 in Group $\mathrm{K}$ and 7 in Group C (Table 3). One vial of 10 milligrams of metoclopramide was given to 5 patients in Group $\mathrm{K}$ and 1 patient in Group C.

Table 3. No. of patients provided with additional analgesic medications

\begin{tabular}{lcc} 
Medication & Group K & Group C \\
\hline Tramadol & 2 & 2 \\
Diclofenac & 1 & 5 \\
Metoclopramide & 5 & 1 \\
\hline
\end{tabular}




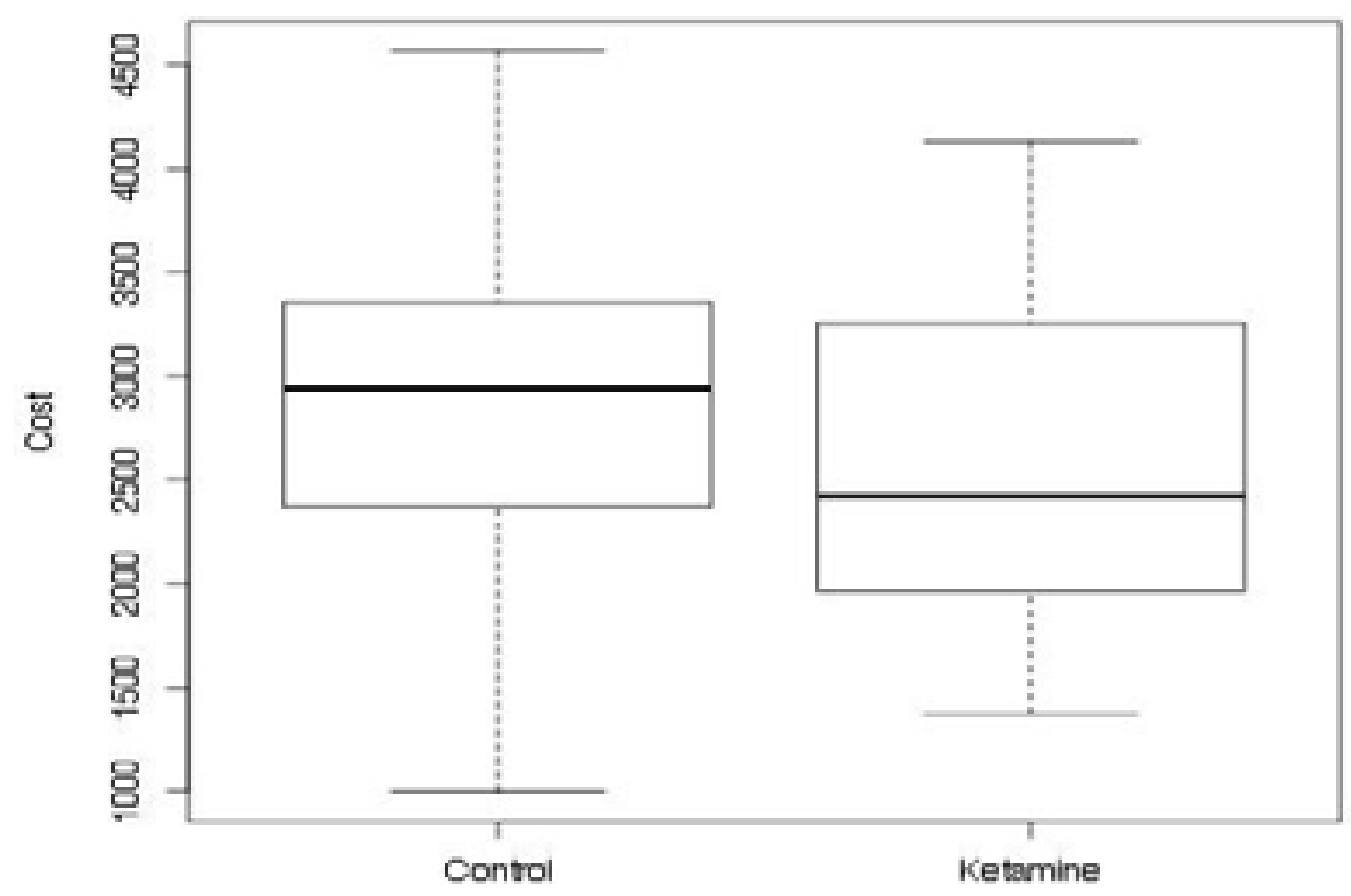

Figure 2: Overall cost for post-operative pain management

\section{Secondary outcomes}

\section{Clinical evaluation}

Pain scores during the first 24 hours after surgery were comparable in the two groups with a mean value of 3.71 in Group $\mathrm{K}$ and 3.91 in Group C. There was no statistically significant difference between the two groups (Fig. 3). Eight patients in Group $\mathrm{K}$ experienced vomiting, compared to 4 patients in Group C. Three patients in each group had nausea, while one patient in each group had minor skin reaction. Neither major or other minor side effects nor psycho-mimetic effects related to ketamine were observed in post-operative period in both groups. In Group K, three patients reported nausea, eight vomiting and one suffered from pruritus. Similarly, in Group $\mathrm{C}$, three patients reported nausea, four vomiting and one pruritus. In both groups no respiratory depression $(\mathrm{RR}<$ 10 breaths/min) was observed.

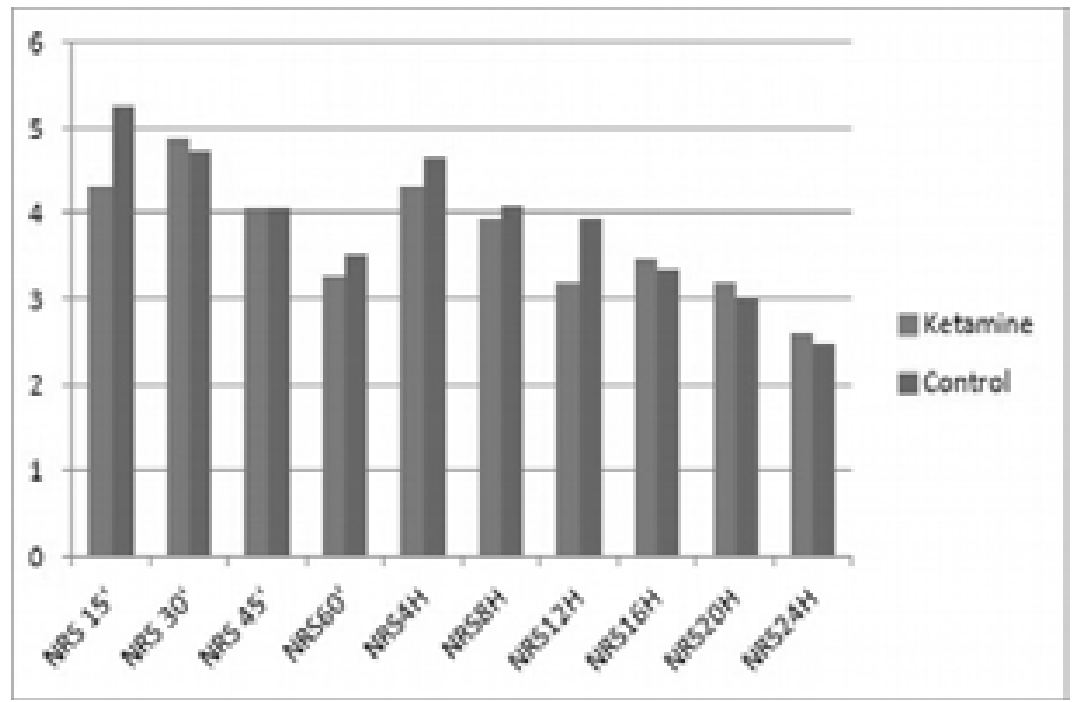

Figure 3: 


\section{Analgesic acceptance}

At the end of the 24-hour pain assessment, 32 patients $(69.6 \%)$ reported a satisfaction score of 4 (excellent), while the remaining $14(30.4 \%)$ indicated a score of 3 (very good). There was no statistically significant difference between the two groups (data not shown).

\section{Hospital length of stay}

Hospital length of stay ranged from 1 to 30 days with a mean value of 8.2 and 4.2 days for Group $K$ and Group $\mathrm{C}$, respectively. There was no statistically significant difference between the two groups $(p=0.24)(95 \%$ CI for the difference: $-1.8,7.2)$ even after controlling for age, gender and ASA classification.

\section{Discussion}

This randomized controlled trial explored the overall medication cost of acute post-operative pain treatment in the first 24 hours after surgery when intra-operative lowdose ketamine was combined to intravenous morphine. To date, this research seems to be the first scientific effort to assess the influence of ketamine in reducing the medication cost of post-operative pain relief. Moreover, it represents an attempt to define a feasible method to treat post-operative acute pain in settings characterized by limited medical resources, such as developing countries or disaster situations.

This study failed to demonstrate a significant cost reduction of post-operative pain management when pre-emptive analgesia with low-dose ketamine was performed. Interestingly, the overall consumption of morphine in the post-operative period was non-significantly different in the two groups, in contrast with previously published studies that supported ketamine's opioid-sparing effect. ${ }^{12,19,24}$

Our results showed no difference in either post-operative pain intensity or patients' satisfaction between the two groups in any of the measurements performed. Pain scores were low in both groups, indicating the provision of a satisfactory analgesic protocol and suggesting the absence of additional effect on pain provided by ketamine. While several of the above studies have demonstrated less post-operative pain in patients receiving pre-emptive analgesia with ketamine, others have reported no bene$\mathrm{fit}^{25-29}$.
A plausible explanation for these contradictory results could be ascribed to the broader presence of major surgery procedures in studies reporting no improvement of post-operative pain scores; in these cases, pre-operative ketamine might not have been able to stop central sensitization ${ }^{21}$. Interestingly, in their meta-analysis of randomized clinical trials, Yang et al. ${ }^{18}$ found little association between the pre-emptive dose of ketamine and its analgesic efficacy after surgery. Remarkably, most of the studies included in this meta-analysis reported the absence of any beneficial effect of pre-emptive ketamine in improving pain scores in the late post-operative period $(>12-24 \mathrm{~h})^{12}$.

Regarding the need for additional analgesia, tramadol was equally administered in both groups while diclofenac was administered more frequently in control patients. There is little explanation for this fact as the administration of either of these two drugs was left to the free will of the health operator. Anecdotally, the study of Wang et al. that was conducted in patients undergoing transurethral resection of prostate, found a smaller request of tramadol in the ketamine group ${ }^{21}$.

Our findings showed no statistical difference also in major or minor side effects between study groups. Similarly, other studies have already reported on the safety of pre-emptive analgesia with ketamine ${ }^{12,19-21}$. Specifically, the low doses used in this study would be responsible for the lack of central nervous system symptoms such as hallucinations etc. It is remarkable that, while most of these studies have focused on a certain type of surgery (e.g. abdominal surgery, orthopedic surgery, renal surgery etc. $)^{12,19}$, our study embraced a fair variety of surgical interventions which may suggest ketamine as a safe drug regardless of the surgical procedure.

The results of our study showed no significant difference between the two groups regarding hospital length of stay, indicating that pre-emptive ketamine has no impact on recovery profiles and patients' functional outcome.

Of note, Himmelseher and co-workers ${ }^{30}$ highlighted the limited availability of long-term outcome measures in the current literature exploring the intra-operative use of intravenous low-dose ketamine in general anesthesia. Therefore, more research is needed to better investigate the long-term effect of pre-emptive ketamine. In sum- 
mary, the results of this study do not support pre-emptive analgesia with ketamine as a cost-effective strategy for all type of surgery in low-resource settings. Moreover, pre-emptive low-dose ketamine did not show a significant opioid-sparing effect, nor improved post-operative pain scores and patients' satisfaction. Further studies would be advisable in order to solidify or contradict our findings.

\section{Limitations}

The results of this study must be tempered in light of some limitations. First, similarly to a preceding study ${ }^{30}$, it is possible that the inclusion of patients from a variety of medical procedures contributed to increased variance in patients' response to treatment. However, the aim of the present study was to assess the cost-effectiveness of ketamine not as procedure for a single type of surgery but as a general pre-emptive analgesia strategy to be used in a low-resource setting. Second, it is well-known that preoperative low doses of ketamine decrease the possibility of the occurrence of psychiatric/psychomimetic effects but could also be responsible for the negative results obtained. Third, the absence of a consistently available translator may have led to some misunderstanding during pain score assessments preventing, sometimes, the correct evaluation of the patient, especially during his/her recovery from anesthesia in the PACU. In addition, the primary outcome we assessed (overall medication cost in the first 24 hours after surgery) was quite limited. Quality-adjusted life years (QALY) for pain and/ or more time points could be considered in future studies or replicas. Finally, although, we assessed the occurrence of psycho mimetic effects during the first hour after surgery, we couldn't exclude the appearance of late side effects related with ketamine

\section{Conclusion}

This study demonstrated no statistically significant difference for all type of surgery between patients receiving intra-operative low-dose ketamine and patients receiving normal saline in terms of overall medication cost of post-operative pain management. Moreover, our findings do not support the opioid-sparing effect of ketamine. There was no difference between the two groups in pain scores during the first 24 hours, major or other minor side effects, patients' satisfaction and hospital length of stay.

\section{Acknowledgements}

The authors thank Dr. Gianmaria Cammarota and Dr.
Pier Luigi Ingrassia for their suggestions during the initial design of the research study. The research was presented at the 2015 WADEM conference in Cape Town (South Africa).

\section{Conflicts of interest and funding statement}

The authors declare no conflict of interest.

The authors have no sources of funding to declare for this manuscript.

\section{References}

1. World Health Organization. Mass Casualty Management Systems - Strategies and Guidelines for Building Health Sector Capacity. 2007. Retrieved from the internet on October16, 2017. Available at: www.who.int/hac/ techguidance/MCM_guidelines_inside_final.pdf

2. Aisuodionoe-Shadrach OI, Olapade-Olaopa EO, \& Soyannwo OA. Preoperative Analgesia in Emergency Surgical Care in Ibadan. Tropical Doctor 2006; 36(1), 35-36. 3. Imarengiaye CO \& Ande ABA. Demand and Utilisation of Labour Analgesia Service by Nigerian Women. Journal of Obstetrics and Gynaecology 2006; 26(2), 130-132.

4. Hodges SC, Mijumbi C, Okello M, McCormick BA, Walker IA, \& Wilson IH. Anaesthesia Services in Developing Countries: Defining the Problems. Anaesthesia 2007; 62(1), 4-11.

5. King C. Post-operative Analgesia in Rebel Territory in Cote d'Ivoire. Anaesthesia 2005; 60(4), 419-420.

6. Mullan F. Doctors And Soccer Players - African Professionals On The Move. New England Journal of Medicine 2007; 356(5), 440-443.

7. De Lima L, Pastrana T, Radbruch L, \& Wenk R. Cross-Sectional Pilot Study to Monitor the Availability, Dispensed Prices, and Affordability of Opioids around the Globe. Journal of Pain and Symptom Management 2014; 48(4), 649-659.

8. Rampanjato RM, Florence M, Patrick NC, \& Finucane BT. Factors Influencing Pain Management by Nurses in Emergency Departments in Central Africa. Emergency Medicine Journal 2007; 24(7), 475-476.

9. De Lima L, Sweeney C, Palmer JL, \& Bruera E. Potent Analgesics Are More Expensive for Patients in Developing Countries: A Comparative Study. Journal of Pain \& Palliative Care Pharmacotherapy 2004; 18(1), 59-70.

10. Max MB, Payne RG, Edwards W'T (Eds). Principles of Analgesic Use in the Treatment of Acute and Cancer Pain. 4 ed. Greenview, IL: American Pain Society, 1999.

11. World Health Organization. Ketamine: Expert Peer Review On Critical Review Report. 35th Expert Com- 
mittee on Drug Dependence, Hammamet, Tunisia June 4-8, 2012. Retrieved from the Internet on October 16, 2017. Available at: http://apps.who.int/iris/bitstream/10665/77747/1/WHO_trs_973_eng.pdf

12. Corssen G \& Domino EF. Dissociative Anesthesia: Further Pharmacologic Studies and First Clinical Experience with the Phencyclidine Derivative Cl-581. Anesthesia \& Analgesia 1966; 45(1), 29-40.

13. Menigaux C, Fletcher D, Dupont X, Guignard B, Guirimand F, \& Chauvin M. The Benefits of Intra-operative Small-Dose Ketamine on Post-operative Pain after Anterior Cruciate Ligament Repair. Anesthesia \& Analgesia 2000; 90(1), 129-135.

14. Snijdelaar DG, Cornelisse HB, Schmid RL, \& Katz J. A Randomised, Controlled Study of Peri-Operative Low Dose S (+)Ketamine in Combination with Post-operative Patient Controlled S $(+)$ Ketamine and Morphine after Radical Prostatectomy. Anaesthesia 2004; 59(3), 222-228.

15. Guillou N, Tanguy M, Seguin P, Branger B, Campion JP, \& Mallédant Y. The Effects of Small-Dose Ketamine on Morphine Consumption in Surgical Intensive Care Unit Patients after Major Abdominal Surgery. Anesthesia \& Analgesia 2003; 97(3), 843-847.

16. Sveticic G, Gentilini A, Eichenberger U, Luginbühl M, \& Curatolo M. Combinations of Morphine with Ketamine for Patient-Controlled Analgesiaa New Optimization Method. Anesthesiology: The Journal of the American Society of Anesthesiologists 2003; 98(5), 1195-1205.

17. Chia YY, Liu K, Liu YC, Chang HC, \& Wong CS. Adding Ketamine in a Multimodal Patient-Controlled Epidural Regimen Reduces Post-operative Pain and Analgesic Consumption. Anesthesia \& Analgesia 1998; 86(6), 1245-1249.

18. Yang L, Zhang J, Zhang Z, Zhang C, Zhao D, \& Li J. Preemptive Analgesia Effects of Ketamine in Patients Undergoing Surgery. A Meta-Analysis. Acta Cirurgica Brasileira 2014; 29(12), 819-825.

19. Parikh B, Maliwad J, \& Shah VR. Preventive Analgesia: Effect of Small Dose of Ketamine on Morphine Requirement after Renal Surgery. Journal of Anaesthesiology, Clinical Pharmacology 2011; 27(4), 485.

20. Singh H, Kundra S, Singh RM, Grewal A, Kaul TK, \& Sood D. Preemptive Analgesia with Ketamine for Lap- aroscopic Cholecystectomy. Journal of Anaesthesiology, Clinical Pharmacology 2013; 29(4), 478.

21. Wang N, Fu Y, Ma H, \& Wang J. Clinical ResearchRegarding Pre-Emptive Analgesic Effect of Preoperative Ketamine after Tran Surethral Resection of Prostate. Middle East J Anaesthesiol 2015; 23(3), 295-300.

22. Behdad A, Hosseinpour M, \& Khorasani P. Preemptive Use of Ketamine on Post Operative Pain of Appendectomy. The Korean Journal of Pain 2011; 24(3), 137-140. 23. Soper DS. A-priori Sample Size Calculator for Multiple Regression [Software]. 2014; Available at: http:// www.danielsoper.com/statcalc

24. Jonkman K, Dahan A, van de Donk T, Aarts L, Niesters M, \& van Velzen M. Ketamine for Pain. F1000 Research 2017; 6. http://doi.org/10.12688/f1000research.11372.1

25. Biçer F, Eti Z, Saraçoğlu K'T, Altun K, \& Göğüş FY. Does the Method and Timing of Intravenous Ketamine Administration Affect Post-operative Morphine Requirement after Major Abdominal Surgery? Turkish Journal of Anaesthesiology and Reanimation 2014; 42(6), 320.

26. Ong CKS, Lirk P, Seymour RA, \& Jenkins BJ. The Efficacy of Preemptive Analgesia for Acute Post-operative Pain Management: A Meta-Analysis. Anesthesia \& Analgesia 2005; 100(3), 757-773.

27. Dahl V, Ernoe PE, Steen T, Raeder JC, \& White PF. Does Ketamine Have Preemptive Effects in Women Undergoing Abdominal Hysterectomy Procedures? Anesthesia \& Analgesia 2000; 90(6), 1419-1422.

28. Carstensen M \& Møller AM. Adding Ketamine to Morphine for Intravenous Patient-Controlled Analgesia for Acute Post-operative Pain: A Qualitative Review of Randomized Trials. British Journal of Anaesthesia 2010; 104(4), 401-406.

29. Dullenkopf A, Müller R, Dillmann F, Wiedemeier P, Hegi TR, \& Gautschi S. An Intra-operative Pre-Incision Single Dose of Intravenous Ketamine does not have an Effect on Post-operative Analgesic Requirements Under Clinical Conditions. Anaesthesia and Intensive Care 2009; 37(5), 753.

30. Himmelseher S \& Durieux ME. Ketamine for Perioperative Pain Management. Anesthesiology: The Journal of the American Society of Anesthesiologists 2005; 102(1), 211 220. 